\title{
MODAL SELECTION IN UPLAND COTTON
}

\author{
J. T. WALKER \\ Empire Cotton Growing Corporation and Department of Genetics, \\ University of Birmingham*
}

Received 15.iii.64

\section{THE MODAL CONCEPT}

THE origin in 1947 of the modal bulk project in the Uganda Upland cotton variety $\mathrm{BP}_{52}$ was described by Manning (1955, 1956). Manning's objective was to produce " a relatively stable check variety . . . as a basis for measuring advance achieved from selection in the replicated progeny row material " and he considered that this could be done by the successive bulking of seeds from open pollinated plants modal for several traits. Fluctuation about the mean yield was expected to be diminished by the elimination of plants showing extreme values of some components of yield. The attempt was thus aimed at selecting plants with average values for several characters, and is recognisable as an exercise in stabilising selection (Mather, I953). In fact the aims were not achieved, and the failure makes the project of more interest than it would otherwise have been.

\section{PRACTICAL PROCEDURE}

The method of selection is shown diagrammatically in fig. I. It can be seen that there are two phases of selection: the first that of taking a sample of plants from the field, the second that of deriving the modal part of the sample.

Each modal bulk plot is of about $\frac{1}{4}$ acre in area and is sown with seed from plants that passed through the modal filter in the immediately preceding season. Usually about 6000 plants mature: less than one-fifth of the seedlings survive because of losses due to natural selection and artificial thinning of the seedlings in accord with agricultural practice. Field assistants then take a sample of plants that appear to be "reasonably productive" and of "satisfactory plant habit". This subjective procedure, designed to exclude both very poor and very highly yielding plants from the sample, was replaced in the later stages of the experiment by a method for choosing plants at random except for the exclusion of obviously exceptional (e.g. damaged) plants. There is no evidence that the selection of superior plants at this stage causes yield improvement.

The modal programme was started at the same time as a more complex replicated progeny row breeding system using a selection index (Manning, I956; Walker, I960) was initiated. The justification

* Address for correspondence: Cotton Research Station, Namulonge, Kampala, Uganda. 
for starting intense selection based on an index was that the variety had reached a state where further mass selection was unlikely to be useful. The heritability of yield estimated on a single plant basis is extremely low under Uganda conditions, so that emphasis should not

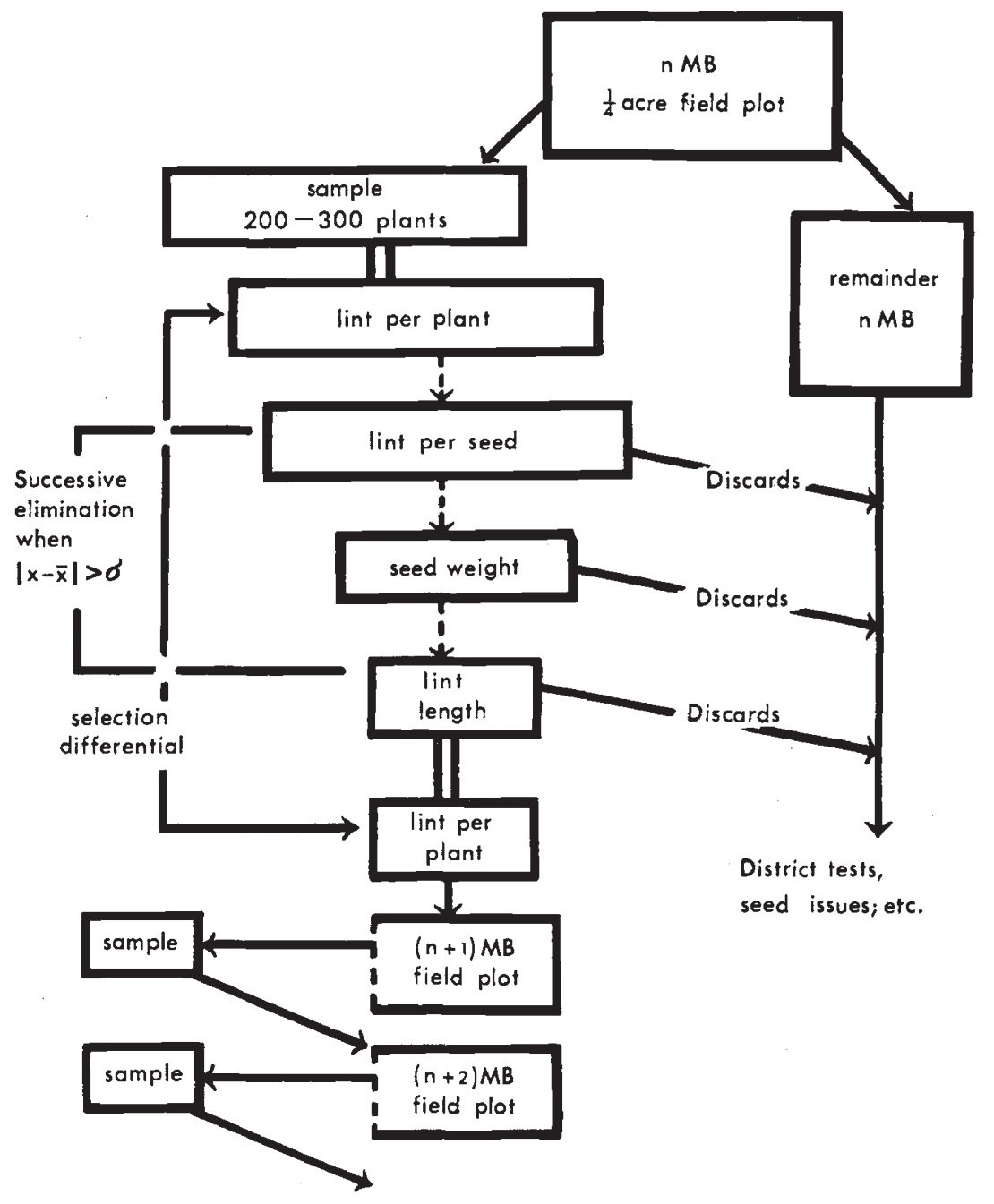

FIG. 1.-The modal bulk selection method.

be placed upon such yields. This must be considered when population yield stabilisation is being tested. The size of the sample varied through the seasons; 500 plants were taken from $\mathrm{BP}_{52} \mathrm{I}_{\mathrm{MB}}$ for the derivation of $2 \mathrm{MB}$, but in subsequent years the number was reduced to 300 and then to 200. The first modal bulk (IMB) was derived from the original bulk using a sample of seed cotton from each of 397 plants, only about $35^{-50}$ per cent. of the total production of the plant being represented. This method of incomplete picking persisted for a few 
years. In later seasons numbered tags were used after plants had been selected early in the fruiting period, and all the seed cotton could be harvested.

The laboratory method for modal selection within the sample has remained unaltered for 15 generations of the modal bulk. The characters are always handled in the same order, an important factor in considerations of selection mechanisms. The seed cotton from each plant is weighed, the lint ginned from the seeds and the amount of lint per seed is calculated. Individual values are grouped in classes and the population distribution examined. All plants that deviate from the population mean by more than one standard deviation in

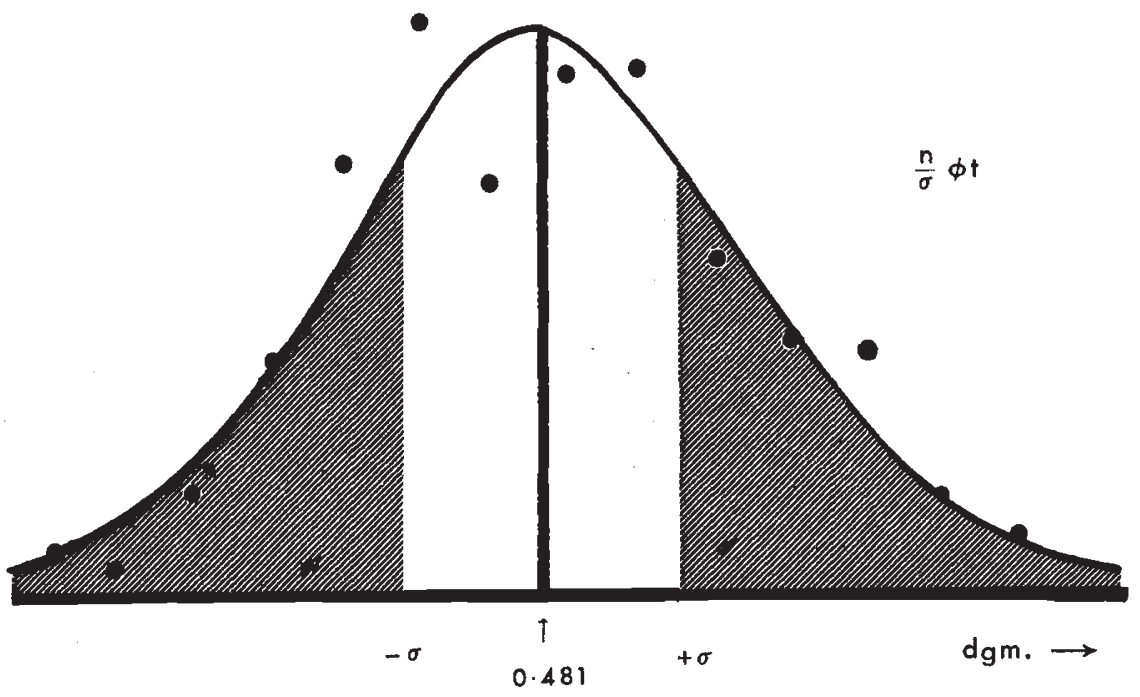

FIG. 2.-Frequency distribution of lint per seed in I I MB grown in I958-59. Normal curve fitted.

either direction are eliminated, so that the criterion for retention is $|x-\bar{x}|<$ s.d. Fig. 2 shows the frequency distribution of lint per seed in II MB, grown in 1958-59, both with grouped data points and after fitting a normal curve. The value of $\chi^{2}$ measuring the deviations from the normal curve is just short of significance at the 5 per cent. level. Seed weight values of surviving plants are examined and the selection process repeated. Then the lint hairs are combed out on a sample of three seeds per plant taken before ginning, and the mean lint " halo" length is measured. Again the modal region of the distribution is chosen, and seed from plants thus selected mixed to provide the source of the modal bulk of the following season, when the whole procedure is repeated.

\section{THE RESULTS OF MODAL SELECTION IN BP52}

Widespread interest was aroused when Manning reported (1955) that yield stabilisation had not occurred in the $\mathrm{BP}_{52}$ modal bulk 
TABLE

Variation in three traits

\begin{tabular}{|c|c|c|c|c|c|c|}
\hline \multirow{2}{*}{ Season } & \multirow{2}{*}{ Population } & \multirow{2}{*}{ Total plants } & \multicolumn{4}{|c|}{ Lint per seed (all plants) } \\
\hline & & & $\begin{array}{l}\text { Mean } \\
\text { (dgm.) }\end{array}$ & $\begin{array}{l}\text { Standard } \\
\text { deviation }\end{array}$ & $\begin{array}{c}\text { Coefficient } \\
\text { of variation }\end{array}$ & $\begin{array}{l}\text { Number } \\
\text { retained }\end{array}$ \\
\hline $1947-48$ & $\begin{array}{l}\text { Original } \\
\text { bulk }\end{array}$ & 396 & $0 \cdot 464$ & $0.06_{5} \mathrm{I}$ & $14 \cdot 0$ & 323 \\
\hline $1948-49$ & $\mathrm{IMB}$ & $5^{00}$ & 0.522 & 0.0472 & $9 \cdot 0$ & 349 \\
\hline $\begin{array}{l}1949-50 \\
\end{array}$ & $2 \mathrm{MB}$ & 499 & $0 \cdot 44^{8}$ & 0.0472 & 10.5 5 & 340 \\
\hline $195^{0-5} \mathrm{I}$ & 3MB & 500 & 0.483 & 0.0495 & IO I I & $35 \mathrm{I}$ \\
\hline $1951-52$ & $4 \mathrm{MB}$ & 299 & 0.503 & 0.0354 & $7 \cdot I$ & $22 I$ \\
\hline $1952-53$ & $5 \mathrm{MB}$ & 300 & 0.485 & 0.0530 & 10.9 & $2 I_{5}$ \\
\hline I953-54 & $6 \mathrm{MB}$ & 200 & 0.494 & 0.0495 & 10.0 & I 38 \\
\hline $\begin{array}{l}1954-55 \\
I\end{array}$ & ${ }_{7} \mathrm{MB}$ & 300 & 0.488 & 0.0531 & $10 \cdot 9$ & 215 \\
\hline $\begin{array}{l}1955-56 \\
1956\end{array}$ & $8 \mathrm{MB}$ & 300 & 0.472 & 0.0431 & $9 \cdot \mathrm{I}$ & 220 \\
\hline $\begin{array}{l}1956-57 \\
1956\end{array}$ & $9 \mathrm{MB}$ & 298 & 0.536 & $0 \cdot 0495$ & $9 \cdot 2$ & 221 \\
\hline $\begin{array}{l}1957-58 \\
1958\end{array}$ & IOMB & 200 & 0.513 & 0.0659 & 13.0 & I 43 \\
\hline $\begin{array}{l}\text { I } 958-59 \\
\end{array}$ & I I $\mathrm{MB}$ & 200 & $0.48 \mathrm{I}$ & 0.0680 & $14 \cdot 2$ & 137 \\
\hline $\begin{array}{l}1959^{-60} \\
1\end{array}$ & $12 \mathrm{MB}$ & 200 & 0.529 & $0.056 \mathrm{I}$ & $10 \cdot 6$ & $14 \mathrm{I}$ \\
\hline $1960-61$ & ${ }_{1} 3 \mathrm{MB}$ & 200 & 0.488 & 0.0588 & $12 \cdot 0$ & I 44 \\
\hline $\begin{array}{l}1961-62 \\
196\end{array}$ & $14 \mathrm{MB}$ & 200 & 0.480 & 0.0621 & 12.9 & $\begin{array}{l}142 \\
142\end{array}$ \\
\hline I $962-63$ & I $5 \mathrm{MB}$ & 200 & 0.520 & 0.0402 & $7 \cdot 7$ & 132 \\
\hline
\end{tabular}

TABLE

Variation in lint yield per plant

\begin{tabular}{|c|c|c|c|c|c|c|}
\hline \multicolumn{7}{|c|}{ Lint per plant (all plants) } \\
\hline Season & Population & Total plants & $\begin{array}{c}\text { Mean } \\
(\text { dgm. })\end{array}$ & $\begin{array}{l}\text { Standard } \\
\text { deviation }\end{array}$ & $\begin{array}{c}\text { Coefficient } \\
\text { of variation } \\
\text { (per cent.) }\end{array}$ & $\begin{array}{l}\text { Number } \\
\text { selected }\end{array}$ \\
\hline เ947-48 & $\begin{array}{l}\text { Original } \\
\text { bulk }\end{array}$ & 396 & I $18 \cdot 0$ & $72 \cdot 3$ & 55.4 & 211 \\
\hline І $948-49$ & I MB & 500 & $210 \cdot 8$ & $59 \cdot 3$ & $27 \cdot 9$ & 177 \\
\hline I949-50 & $2 \mathrm{MB}$ & 499 & I $4^{8 \cdot 6}$ & $46 \cdot I$ & $3 \mathrm{I} \cdot 2$ & 171 \\
\hline $1950-51$ & $3^{\mathrm{MB}}$ & 500 & 302.4 & $108 \cdot 7$ & 35.9 & 171 \\
\hline $1951-52$ & $4 \mathrm{MB}$ & 299 & 306.6 & $102 \cdot 0$ & 33.3 & I 25 \\
\hline I $952-53$ & ${ }_{5} \mathrm{MB}$ & 300 & I $76 \cdot 2$ & $100 \cdot I$ & $57 \cdot 4$ & 108 \\
\hline I953-54 & $6 \mathrm{MB}$ & 200 & $242 \cdot 4$ & $72 \cdot 5$ & $29 \cdot 9$ & 69 \\
\hline ז954-55 & 7MB & 300 & $189 \cdot 4$ & $50 \cdot I$ & $26 \cdot 4$ & 106 \\
\hline I $955^{-56}$ & $8 \mathrm{MB}$ & 300 & $403^{\circ}$ & $104 \cdot 7$ & $26 \cdot 0$ & IIO \\
\hline I $956-57$ & $9 \mathrm{MB}$ & 298 & $279 \cdot 0$ & 88.4 & $3 I \cdot 7$ & $9^{8}$ \\
\hline $1957-58$ & I oMB & 200 & $78 \cdot 3$ & $28 \cdot 5$ & $3^{6 \cdot 4}$ & 6̆o \\
\hline ז $958-59$ & I I $\mathrm{MB}$ & 200 & $93 \cdot 6$ & 33.9 & $36 \cdot 2$ & 89 \\
\hline I 959-6o & I $2 \mathrm{MB}$ & 200 & 157.5 & $42 \cdot 9$ & $27 \cdot 3$ & $6 \mathrm{I}$ \\
\hline I $960-6$ I & $3 \mathrm{MB}$ & 200 & $18 \mathrm{I} \cdot 2$ & $48 \cdot 2$ & 26.6 & $5^{8}$ \\
\hline І $961-62$ & $14 \mathrm{MB}$ & 200 & $83 \cdot I$ & 35.7 & $43^{\circ} 0$ & 75 \\
\hline $1962-63$ & I $5 \mathrm{MB}$ & 200 & $324^{\circ} 0$ & I $32 \cdot 6$ & $40 \cdot 9$ & 74 \\
\hline
\end{tabular}


under modal selection

\begin{tabular}{|c|c|c|c|c|c|c|c|}
\hline \multicolumn{4}{|c|}{$\begin{array}{l}\text { Seed weight } \\
\text { (survivors from selection for lint per seed) }\end{array}$} & \multicolumn{4}{|c|}{$\begin{array}{l}\text { Lint length } \\
\text { (survivors from selection for seed weight) }\end{array}$} \\
\hline $\begin{array}{c}\text { Mean } \\
(\text { dgm. }\end{array}$ & $\begin{array}{l}\text { Standard } \\
\text { deviation }\end{array}$ & $\begin{array}{l}\text { Coefficient } \\
\text { of variation }\end{array}$ & $\begin{array}{l}\text { Number } \\
\text { retained }\end{array}$ & $\begin{array}{l}\text { Mean } \\
(\mathrm{mm} .)\end{array}$ & $\begin{array}{l}\text { Standard } \\
\text { deviation }\end{array}$ & $\begin{array}{l}\text { Coefficient } \\
\text { of variation }\end{array}$ & $\begin{array}{l}\text { Number } \\
\text { retained }\end{array}$ \\
\hline \multicolumn{4}{|c|}{ Not used in this season } & $30 \cdot 27$ & $1 \cdot 83$ & $6 \cdot 0$ & 211 \\
\hline $1 \cdot 047$ & $0 \cdot \log ^{1} 4$ & $8 \cdot 7$ & $25 \mathrm{I}$ & 29.47 & 1.58 & $5 \cdot 4$ & 177 \\
\hline$I \cdot 041$ & 0.0836 & $8 \cdot 0$ & 233 & $3^{\mathrm{I}} \cdot 4^{8}$ & $1 \cdot 65$ & $5 \cdot 2$ & 171 \\
\hline $1 \cdot 021$ & 0.0700 & $6 \cdot 8$ & 250 & $33 \cdot 60$ & $1 \cdot 60$ & $4 \cdot 7$ & 171 \\
\hline $1 \cdot 013$ & 0.0663 & $6 \cdot 5$ & 164 & $33 \cdot 84$ & $1 \cdot 46$ & $4 \cdot 2$ & 125 \\
\hline $1 \cdot 057$ & 0.0744 & $7 \cdot 0$ & 155 & 34.87 & $1 \cdot 60$ & $4 \cdot 6$ & 108 \\
\hline $1 \cdot 012$ & 0.0743 & $7 \cdot 3$ & 98 & $34 \cdot 87$ & $1 \cdot 48$ & $4 \cdot 2$ & 69 \\
\hline 0.982 & 0.0733 & 7.5 & 162 & $35 \cdot 12$ & $1 \cdot 74$ & 5. & 106 \\
\hline $0 \cdot 978$ & 0.06 & $6 \cdot 2$ & 163 & $34 \cdot 64$ & 1.56 & $4 \cdot 5$ & 110 \\
\hline $1 \cdot 105$ & 0.0680 & $6 \cdot 1$ & 160 & $34 \cdot 33$ & $1 \cdot 9$ & 5 & 98 \\
\hline$I \cdot 136$ & 0.0757 & $6 \cdot 7$ & 106 & $34: 35$ & 1.5 & $4 \cdot 6$ & 60 \\
\hline 1.059 & 0.0834 & $7 \cdot 9$ & 114 & 34.80 & 1.88 & $5 \cdot 4$ & 89 \\
\hline 1.052 & 0.0655 & $6 \cdot 2$ & 84 & $34 \cdot 97$ & $1 \cdot 98$ & 5 . & 61 \\
\hline 0.998 & $0.073^{\circ}$ & $7 \cdot 3$ & 94 & $35 \cdot 28$ & $1 \cdot 72$ & $4 \cdot 9$ & 70 \\
\hline 0.981 & 0.0722 & 7.4 & 107 & $34 \cdot 18$ & $2 \cdot 08$ & $6 \cdot I$ & 79 \\
\hline 0.972 & 0.0657 & $6 \cdot 8$ & 100 & & New measuri & method used & \\
\hline
\end{tabular}

2

with modal selection

Lint per plant (survivors from selection for lint length)

\begin{tabular}{|c|c|c|c|c|c|c|}
\hline $\begin{array}{c}\text { Mean } \\
\text { (dgm.) }\end{array}$ & $\begin{array}{l}\text { Standard } \\
\text { deviation }\end{array}$ & $\begin{array}{c}\text { Coefficient } \\
\text { of variation } \\
\text { (per cent.) }\end{array}$ & Seed for & $\begin{array}{l}\text { Selection } \\
\text { advance } \\
\text { (per cent.) }\end{array}$ & $\begin{array}{l}\text { Cumulative } \\
\text { selection } \\
\text { advance }\end{array}$ & $\begin{array}{c}\text { Mean } \\
\text { annual } \\
\text { increase }\end{array}$ \\
\hline $127 \cdot 2$ & $69 \cdot 0$ & $54 \cdot 1$ & I $\mathrm{MB}$ & $+7 \cdot 8$ & $+7: 8$ & $7 \cdot 80$ \\
\hline 219.0 & $55 \cdot I$ & $25 \cdot 2$ & $2 \mathrm{MB}$ & +3.9 & $+\mathrm{II} \cdot 7$ & $5 \cdot 85$ \\
\hline 153.2 & 43.2 & $28 \cdot 2$ & $3 \mathrm{MB}$ & $\begin{array}{r}3 \cdot \\
+3 \cdot 1\end{array}$ & $\begin{array}{r}+14.8 \\
\end{array}$ & $\begin{array}{l}3.03 \\
4.93\end{array}$ \\
\hline $302 \cdot 3$ & 99.3 & $3^{2} \cdot 8$ & $4 \mathrm{MB}$ & 0 & +14.8 & $3 \cdot 70$ \\
\hline $310 \cdot 2$ & 99.0 & $3^{1} \cdot 8$ & $5 \mathrm{MB}$ & $+1 \cdot 2$ & $+16 \cdot 0$ & $3 \cdot 20$ \\
\hline 187.2 & $92 \cdot 8$ & 49.5 & $6 \mathrm{MB}$ & $+6 \cdot 2$ & $+22 \cdot 2$ & $3 \cdot 70$ \\
\hline $257 \cdot 8$ & 69.1 & $26 \cdot 8$ & $7 \mathrm{MB}$ & $+6 \cdot 3$ & $+28 \cdot 5$ & 4.07 \\
\hline 192.7 & $48 \cdot 4$ & $25 \cdot 1$ & $8 \mathrm{MB}$ & +1.7 & $\begin{array}{r}+30 \cdot 2 \\
\end{array}$ & $3 \cdot 78$ \\
\hline $421 \cdot 6$ & $103 \cdot 2$ & $24 \cdot 6$ & $9 \mathrm{MB}$ & +46 & $\begin{array}{r}34.8 \\
\end{array}$ & 3.87 \\
\hline $284 \cdot 0$ & $93^{\circ} 0$ & $3^{2} \cdot 7$ & $10 \mathrm{MB}$ & $+1 \cdot 8$ & +36.6 & $3 \cdot 66$ \\
\hline 79.9 & $28 \cdot 1$ & $35 \cdot \mathrm{I}$ & I $\mathrm{MB}$ & $+2 \cdot I$ & $+3^{8 \cdot 7}$ & 3.52 \\
\hline 99.3 & $3^{6} \cdot 3$ & $36 \cdot 6$ & $12 \mathrm{MB}$ & $+6 \cdot 2$ & $\begin{array}{r}+449 \\
\end{array}$ & 3.74 \\
\hline 156.6 & 43.9 & $28 \cdot 0$ & I3MB & -0.6 & +443 & $3 \cdot 4 \mathrm{I}$ \\
\hline 172.4 & $43 \cdot 3$ & & $14 \mathrm{MB}$ & $-4^{\cdot} \cdot 8$ & +39.5 & $2 \cdot 84$ \\
\hline 88.8 & 33.4 & $37 \cdot 6$ & $15 \mathrm{MB}$ & +6.9 & $+46 \cdot 4$ & 3.09 \\
\hline $35^{1} \cdot 8$ & $142 \cdot 8$ & $40 \cdot 6$ & $16 \mathrm{MB}$ & +8.6 & $+55^{\circ} 0$ & $3 \cdot 44$ \\
\hline
\end{tabular}


populations, and that there was evidence of an upward trend. A comparison in a yield trial between $7 \mathrm{MB}$ and plants grown from freshly regenerated stored seed of the original bulk showed an implied improvement of 4.3 per cent. over four replications. Tests in district variety trials in two successive seasons using 13 and 6 sites respectively gave an average increase of 2.5 per cent. per generation. Manning (1955) averaged the two improvement estimates arithmetically and assumed an advance of 3.4 per cent. per year, although the estimate obtained by weighting the advances in accordance with the number of replications giving the two sets of information is only 2.55 per cent. per generation. Manning recently (1963) advocated modal bulking as a useful breeding method in view of "the moderate annual yield advance . . . secured over 12 generations" although it was stated that the mechanism by which the advance had been achieved was not understood.

Results from the $\mathrm{BP}_{52}$ modal programme are dealt with in two parts.

\section{(i) Results from the sample populations}

Values of the mean, standard deviation and coefficient of variation of each of the three traits under selection are given in table I. Similar statistics for sample mean yields and selected plant mean yields are included in table 2, together with estimates of advance under selection. From these two tables, figs. 3 and 4 have been constructed. Linear regression lines have been fitted to estimate trends in the characters over the generations of selection, but the actual values are also indicated on the graphs. Regressions of means upon generation number were fitted directly; regressions involving variances used data transformed to $\log _{10}$, but there was virtually no difference between transformed and untransformed results.

The mean average value of lint per seed increased over i 5 years from 0.480 dgm. to $0.508 \mathrm{dgm}$., a very slight improvement of only 0.002 dgm. per generation. The gradient of the regression line measuring the rate of increase is $b=0.018 \pm 0.013$, a slope which does not differ significantly from zero $(0 \cdot 1<\mathrm{P}<0 \cdot 2)$. It can also be seen that the variance of the character showed no significant trend over the years, as $b=0.004 \pm 0.005$ and the departure from zero slope is non-significant $(0 \cdot 4<\mathrm{P}<0 \cdot 5)$. In so far as the mean did not change significantly, the trait lint per seed responded in accordance with expectation for stabilising selection, but differed in that there was no decrease in variance.

The average seed weight decreased slightly from I 044 to $\mathrm{I} \cdot 020$ dgm. over the seasons (equal to 0.0017 per generation), and the variance dropped from 0.785 to 0.675 . The respective regression coefficients are $b=-0.017 \pm 0.029(0.5<\mathrm{P}<0.6)$ and $b=-0.008$ $\pm 0.004(0 \cdot 1<P<0 \cdot 2)$ so that no significant change is detectable by testing for departure from zero slope. Here again we can say that 
both mean and variance remained essentially unaltered by the selection.

Lint length, the third character subjected to the selection process, reacted differently, for definite changes occurred in both the mean and dgm.
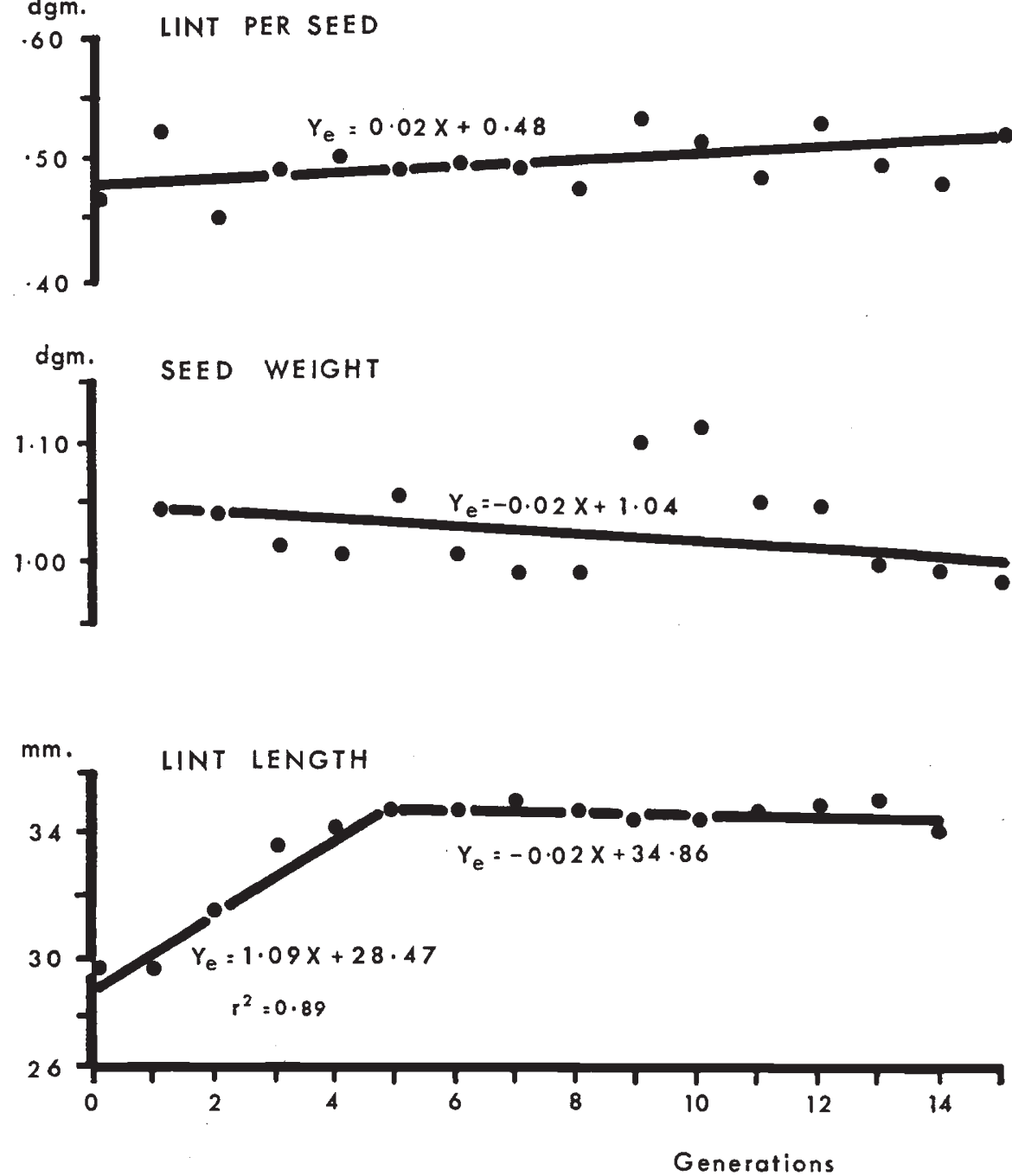

Frg. 3.-Variation in the means of three characters under modal selection. Linear regression lines fitted.

variance of the trait. It can be seen from figs. 3 and 4 that mean lint length increased rapidly from $29.5 \mathrm{~mm}$. to $34^{\circ} 9 \mathrm{~mm}$. over five generations, whilst the variance decreased slightly. The linear regression line accounts for 89 per cent. of the variability of the means during this period of increase in lint length. The regression coefficient for the means is $b=\mathrm{I} \cdot 086 \pm 0 \cdot \mathrm{I} 90$ which does not differ significantly from unity $(0 \cdot 6<\mathrm{P}<0 \cdot 7)$. The coefficient for the variance trend is 
$b=-0.045 \pm 0.022$, and this does not differ significantly from zero $(0 \cdot \mathrm{I}<\mathrm{P}<0 \cdot 2)$, so that over the period of length extension the drop in variance is not statistically significant. During the next nine

Std.
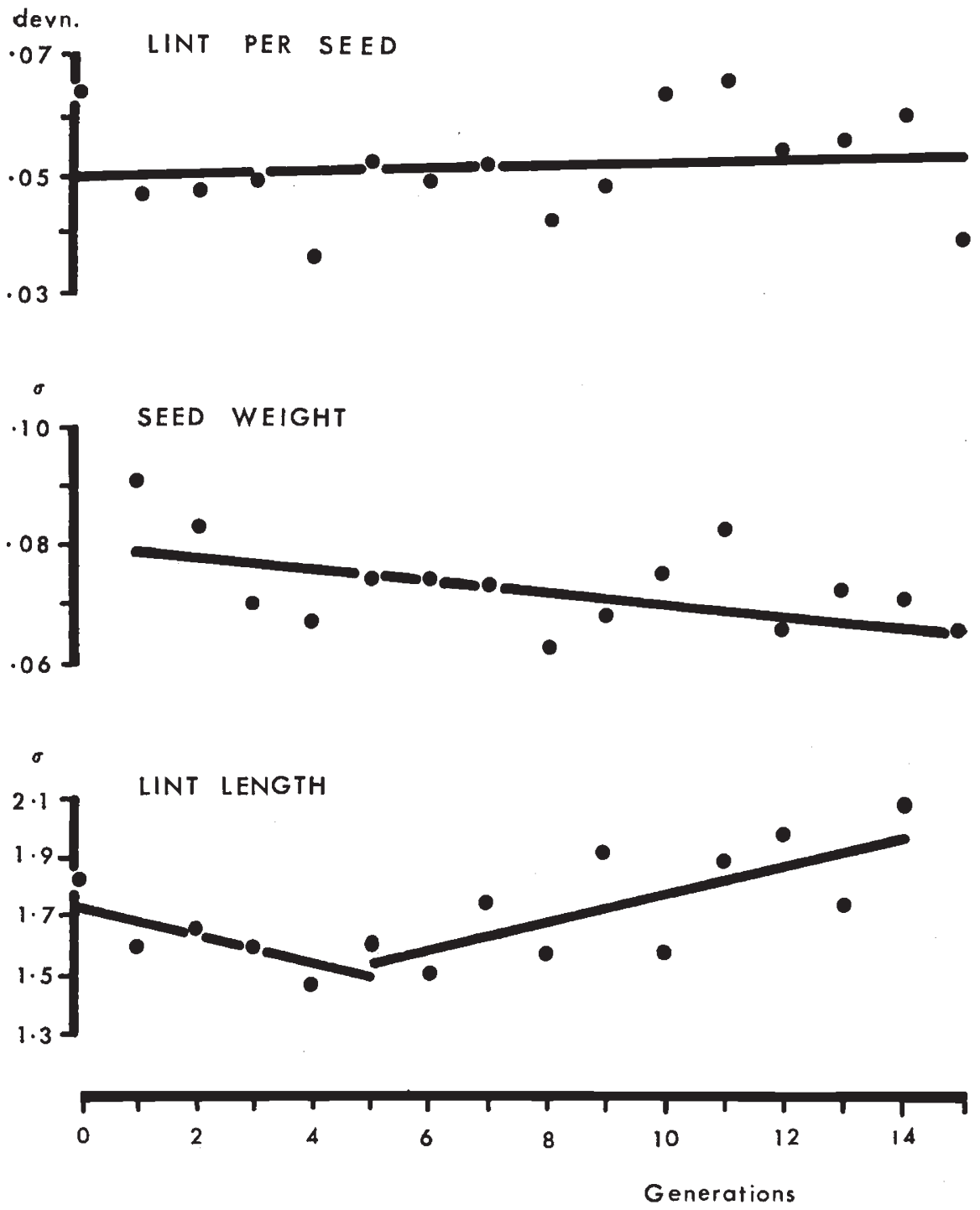

Fig. 4.-Changes in the variances of three characters under modal selection. Linear regressions fitted.

seasons, however, the picture is very different: length remained steady, with $b=-0.020 \pm 0.042(0.6<\mathrm{P}<0.7)$ but the variance increased slightly by an amount that was statistically detectable: $b=0.047$ $\pm 0.017(0.02<\mathrm{P}<0.05)$. This increase in variance is against orthodox expectation during stabilisation of the mean. 
Yield is more difficult to deal with. The mean lint yield per plant from the annual sample shows no discernible trend; values are extremely variable, as are those of the variances. Fluctuation is due to the fact that the whole produce of each plant in the sample is not always picked, and also because the cotton is raingrown in an area of erratic rainfall and the seasonal variation in yield is therefore great.

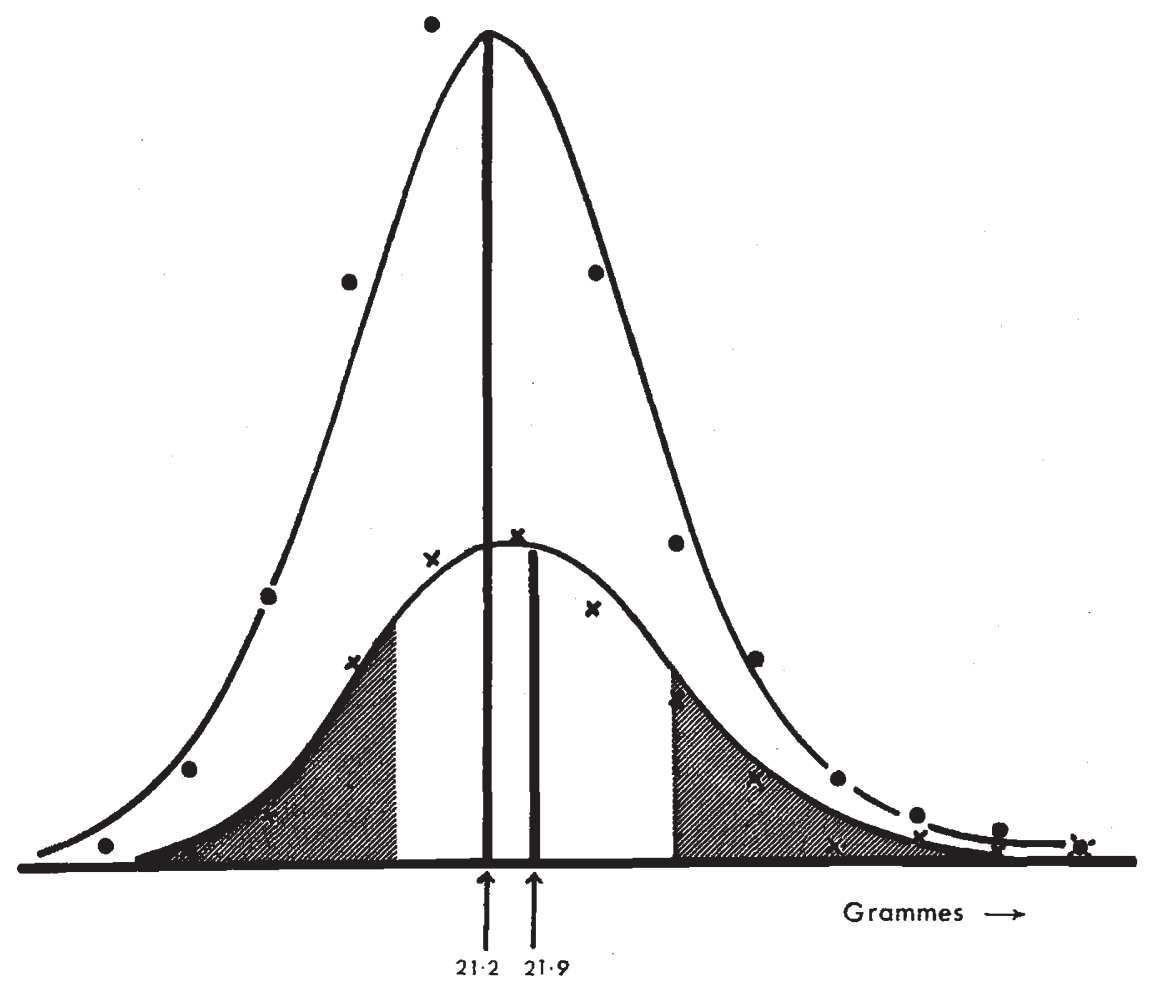

FIG. 5. -Difference in mean yield of the selected portion and of the whole sample. Normal curves fitted.

Such data are clearly useless for trend estimation, only fully replicated yield trials with controls being acceptable for this purpose. It is worth considering, however, the difference in yield between the mean of the whole sample and that of the selected sub-population, as illustrated in fig. 5. These differences represent positive advances in 13 out of 16 generations, as shown in fig. 6. The advances are, only partially heritable, realised gains falling short of expectation based on these estimates.

A consideration thus far of results from the samples leads to the following conclusions:-

I. A definite change in lint length occurred during the first five seasons, after which length stabilised around a value of $35 \mathrm{~mm}$. 
The lint length of the original bulk was about $30 \mathrm{~mm}$. Between generations 5 and 15 length was constant, but its variance, which had shown mainly random fluctuation for five seasons, increased slightly but significantly.

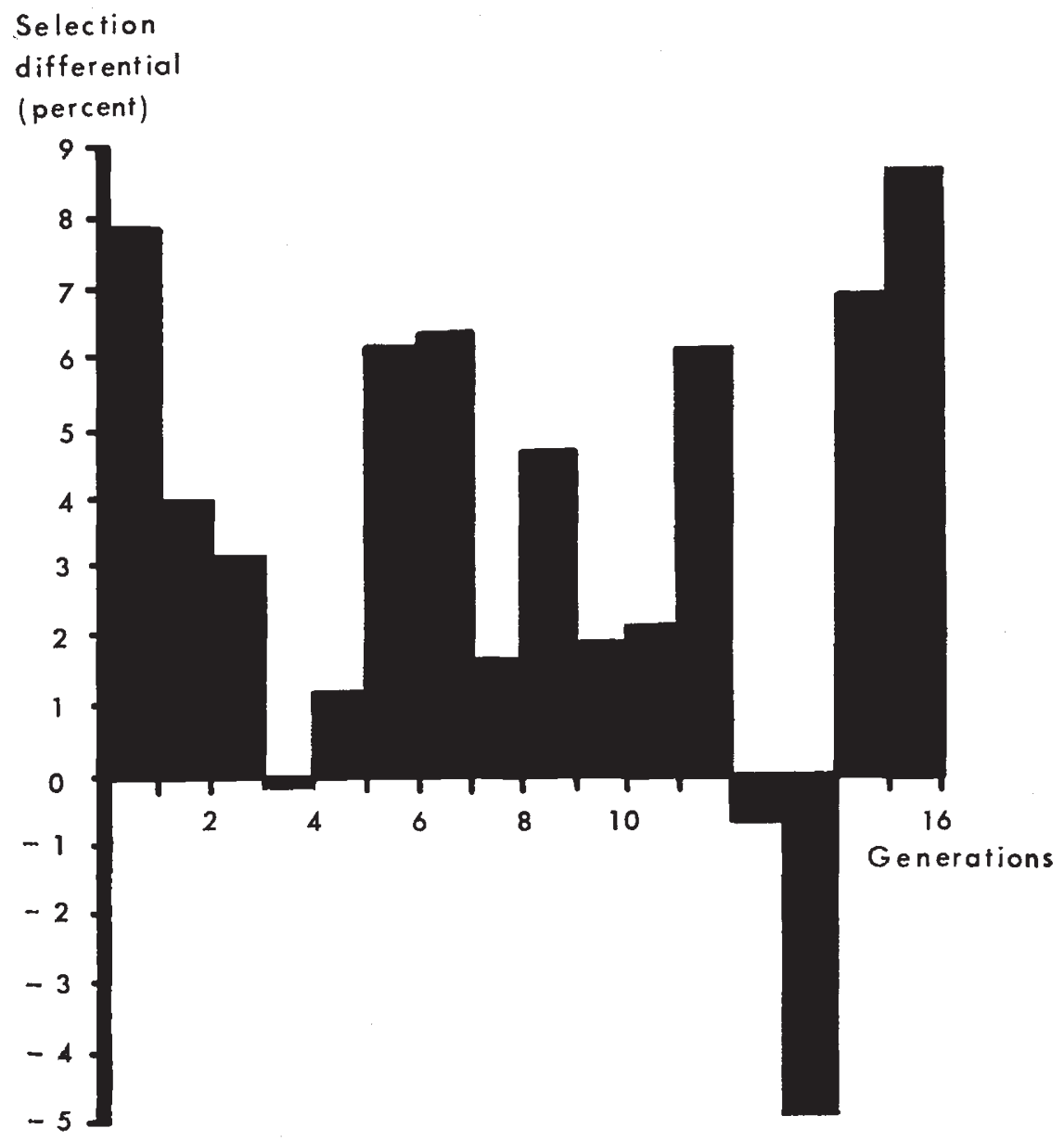

Fic. 6.-Annual selection differentials for lint per plant in the $\mathrm{BP}_{52}$ modal bulks.

2. Changes in the means and variance of both lint per seed and seed weight were non-significant.

3. Variability of single plant yields was too large for them to be of use in measuring yield advance.

4. Unusual features of the modal programme are the rise to a new level of lint length and the persistence of the variances. Further evidence is needed before Manning's contention of yield advance can be supported. 


\section{(ii) Results from replicated trials}

We have seen that evidence in support of Manning's claim of an increase in yield potential is unobtainable from the actual modal bulk plots. No controls were grown for comparison and there was no replication, while the overriding factors that determined seasonal mean values were undoubtedly environmental. No attempts were made to stabilise the yielding potential of the plots on which the modal bulks were grown. It is interesting to note that Manning standardised I $\mathrm{MB}$ against the control $\mathrm{BP}_{52}$ selection $\mathrm{K} / 5^{\mathrm{I}}$ at $\mathrm{I}_{4}$ trial sites over a wide area and then, four years later, compared $5 \mathrm{MB}$ with $\mathrm{K} / 5 \mathrm{I}$ (and hence indirectly with I MB) at six locations. These six locations were actually three sites on the Namulonge farm at which both early and late trials were sown, a total of 18 replications in a confined area. His further test compared $7 \mathrm{MB}$ with a resuscitated "Original bulk", but this was in a replicated progeny row trial at Namulonge with only four replications. It is clear that the data were not extensive, and that consequently the actual values of Manning's advance estimates are somewhat unreliable.

Augmenting Manning's data by results from more recent tests, however, enables us to investigate both the existence and magnitude of the suspected yield trends with increased confidence and accuracy. There is no absolute evaluation of such trends, as the variance of yield response contains items due to genotype by environment interactions, but we should clearly impose stringent restrictions to guard against over-estimation. An analysis is presented based on the following criteria:-

I. All the trials used were grown within, but widely distributed over, the commercial $\mathrm{BP}_{52}$ growing area.

2. Only trials having a coefficient of variation less than 25 per cent. are included.

3. A trial series is only used if at least 15 replications are available.

4. The modal bulk values are directly comparable within the same trial with either the Original bulk, commercial $\mathrm{BP}_{52}$ or with its derivative $\mathrm{K} / 5^{\mathrm{I}}$.

5. Where more than one estimate of relative yield is available for any modal generation (i.e. when a comparison comes from more than one set of trials), then a mean estimate is used weighted in accordance with the number of replications.

The data are presented in table 3 and a linear fit is obtained which gives the following equation estimating modal advance:- $\mathrm{Y}_{e}=0.99$ (Generation) +100.33. This straight line accounts for almost 80 per cent. of the variability. The trend is illustrated in fig. 7 , both fitted regression line and actual points being shown. It is considered that this describes the best available and most representative estimate of the average yield advance shown by the modal bulks in the areas of 202 
TABLE 3

Yield advance showed by successive modal bulks of $B_{52}$. All generations compared directly with $B_{52}$ local, using trials with $C$. of $V .<25$ per cent.

\begin{tabular}{|c|c|c|c|c|c|c|}
\hline $\begin{array}{l}\text { Modal } \\
\text { Bulk }\end{array}$ & $\begin{array}{c}\text { Type of } \\
\text { trial }\end{array}$ & $\begin{array}{l}\text { No. of } \\
\text { reps. }\end{array}$ & $\begin{array}{c}\text { Yield } \\
\text { per cent. } \\
\text { local }\end{array}$ & Generation & $\begin{array}{l}\text { Weighted } \\
\text { mean }\end{array}$ & Expectation \\
\hline I & Line & 70 & $101 \cdot 0$ & 1 & $101 \cdot 0$ & $101 \cdot 38$ \\
\hline 2 & Line & $5^{0}$ & $104 \cdot 2$ & 2 & $104 \cdot 2$ & $102 \cdot 3^{8}$ \\
\hline & & & & 3 & - & 103.37 \\
\hline- & & & & 4 & - & $104 \cdot 37$ \\
\hline 5 & Strain & 18 & 103.9 & 5 & 103.9 & 105.37 \\
\hline 7 & Line & 70 & $102 \cdot 6$ & 7 & $\overline{104} \cdot 6$ & $\begin{array}{l}100.37 \\
107.36\end{array}$ \\
\hline 7 & Strain & 25 & $110 \cdot 1$ & 8 & - & $108 \cdot 36$ \\
\hline & & & & 9 & $111 \cdot 5$ & $109 \cdot 36$ \\
\hline $\begin{array}{r}9 \\
\text { 10 }\end{array}$ & $\begin{array}{l}\text { Strain } \\
\text { Line }\end{array}$ & $\begin{array}{l}25 \\
55\end{array}$ & $111 \cdot 5$ & 10 & 110.3 & $110 \cdot 36$ \\
\hline 10 & Line & 50 & 110.1 & & & \\
\hline
\end{tabular}

Linear regression $\mathrm{Y}_{0}=0.99 \mathrm{X}+100.33$ where $\mathrm{Y}_{0}$ is the expected yield and $\mathrm{X}$ is the generation. $b=0.99, r=0.89, r^{2}=0.79$.

Uganda growing $\mathrm{BP}_{52}$ cotton, but further study of yield trial data shows how very different estimates can be obtained. Considering only those trials grown at Namulonge, for instance, it is clear from fig. 8 that I per cent. is an underestimate of the mean advance at this locality. Only three trials out of twenty-one give estimates of less

\section{\% BP 52}

LOCAL

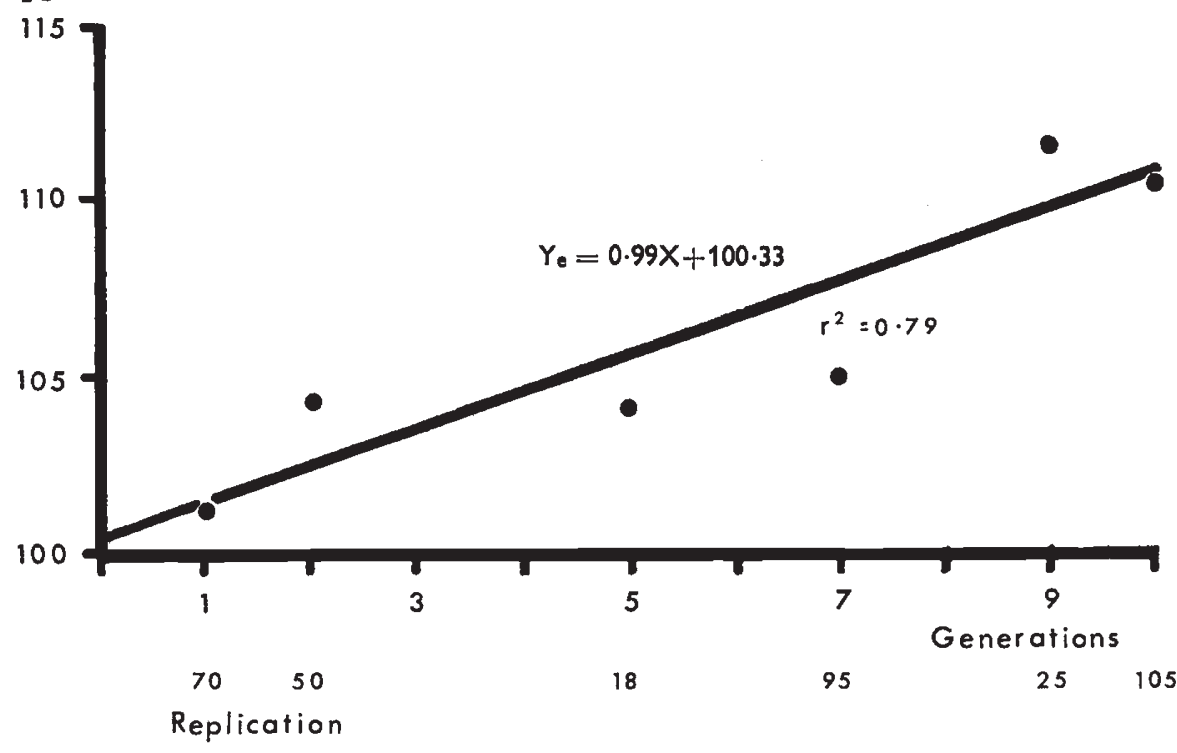

Fig. 7.-The positive yield trend shown by successive $\mathrm{BP}_{52}$ modal bulks tested over a wide area of Uganda. 
than I per cent., 15 are better than 2 per cent. and 8 are more than 3 per cent. It is not possible, however, to obtain a relationship between yield increment and generation that is significant; the best linear

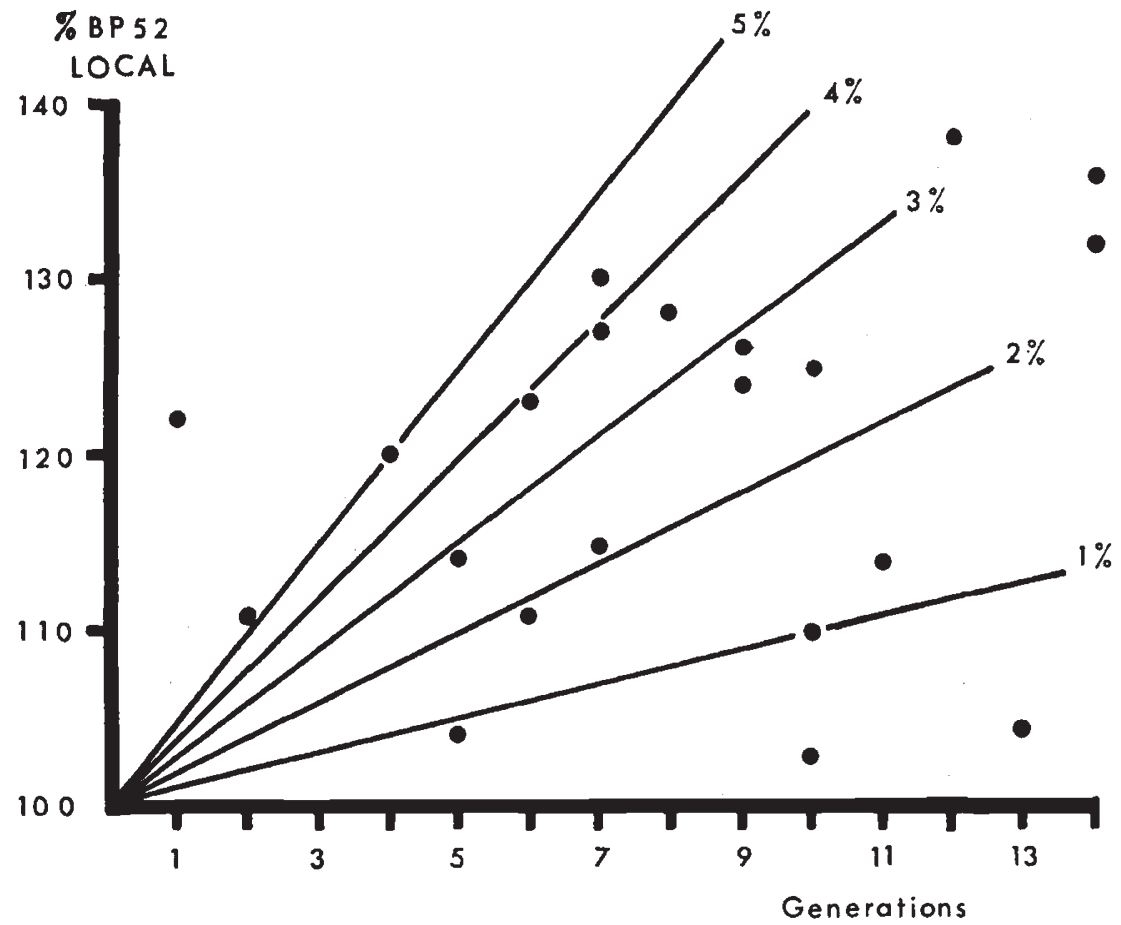

Fic. 8. - Yield increments of $\mathrm{BP}_{52}$ modal bulks tested at Namulonge. Trials with 4,5 or 6 replications.

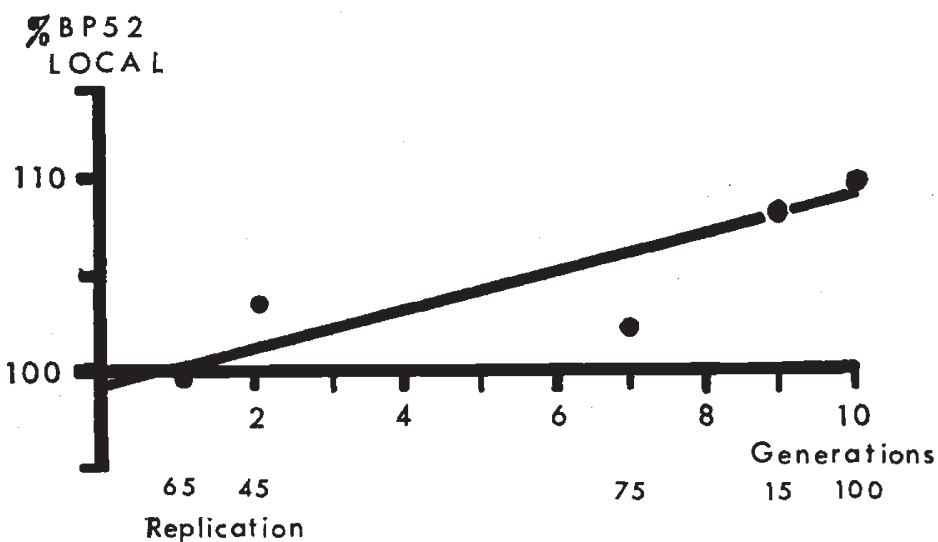

FIG. 9. - The yield trend shown by $\mathrm{BP}_{52}$ modal bulks tested at sites other than Namulonge.

fit accounts for only 8 per cent. of the variation. Estimates from single trials are clearly inadequate for the detection of such small differences in yield. The interaction between genotype and environment is such that the mean advance is less at other sites than at Namulonge. The 
weighted linear regression analysis shown in fig. 9 indicates an advance of 0.85 per cent. per season if results from all trials at Namulonge are excluded. Hereafter, though, the overall advance will be taken to be I per cent. per annum when compared with the original bulk of $\mathrm{BP}_{52}$.

\section{THE CAUSAL MECHANISMS OF ADVANCES OBTAINED UNDER MODAL SELECTION}

(i) Previous hypotheses

Three ways were envisaged by Manning (1955, 1956) by which a form of selection pressure for increased yield could operate in the modal population. The first was simply the possibility of field assistants

TABLE 4

Estimation of selection differentials due to seed number in $B_{52}$ modal bulk

\begin{tabular}{|c|c|c|c|c|c|c|c|c|c|}
\hline Season & $\begin{array}{c}\text { Base } \\
\text { population }\end{array}$ & $\begin{array}{c}\bar{y} \\
\text { Mean lint } \\
\text { yield (gm.) }\end{array}$ & $\sigma_{\nu}$ & $\begin{array}{c}\bar{x} \\
\text { Mean No. } \\
\text { seeds }\end{array}$ & $\sigma_{x}$ & $b_{x y}$ & $\frac{b \sigma_{x}^{2}}{\tilde{x}}$ & $\begin{array}{c}\text { Estimated } \\
\text { percentage } \\
\text { selection } \\
\text { differential } \\
\qquad \bar{y}+\frac{b \sigma_{x}^{2}}{\bar{x}}\end{array}$ & $\begin{array}{c}\text { Actual } \\
\text { percentage } \\
\text { selection } \\
\text { differential } \\
\left(\frac{\Sigma x y}{\Sigma x}\right)-y\end{array}$ \\
\hline $\begin{array}{l}1948-49 \\
1949-50 \\
1955-56 \\
1960-61 \\
1961-62 \\
1962-63\end{array}$ & $\begin{array}{r}\text { I MB } \\
2 \mathrm{MB} \\
8 \mathrm{MB} \\
13 \mathrm{MB} \\
14 \mathrm{MB} \\
15 \mathrm{MB}\end{array}$ & $\begin{array}{r}21 \cdot 08 \\
14 \cdot 86 \\
40 \cdot 30 \\
18 \cdot 12 \\
8 \cdot 31 \\
32 \cdot 40\end{array}$ & $\begin{array}{r}5.93 \\
4.61 \\
10.47 \\
4.82 \\
3.57 \\
13.26\end{array}$ & $\begin{array}{l}403 \cdot 8 \\
331 \cdot 7 \\
853 \cdot 8 \\
348 \cdot 4 \\
186 \cdot 2 \\
681 \cdot 7\end{array}$ & $\begin{array}{r}\text { II } 4 \cdot 7 \\
103 \cdot 5 \\
222 \cdot 0 \\
81 \cdot 6 \\
63 \cdot 8 \\
279 \cdot 5\end{array}$ & $\begin{array}{l}0.0522 \\
0.0446 \\
0.0458 \\
0.0483 \\
0.0479 \\
0.0503\end{array}$ & $\begin{array}{l}\mathrm{I} \cdot 700 \\
\mathrm{I} \cdot 440 \\
2 \cdot 644 \\
0 \cdot 924 \\
\mathrm{I} \cdot 047 \\
5 \cdot 763\end{array}$ & $\begin{array}{r}8 \cdot 1 \\
9 \cdot 7 \\
6 \cdot 6 \\
5 \cdot 1 \\
12 \cdot 6 \\
17 \cdot 8\end{array}$ & $\begin{array}{l}6 \cdot 5 \\
7 \cdot 6 \\
5 \cdot 9 \\
0 \\
I \cdot 8 \\
8 \cdot 5\end{array}$ \\
\hline \multicolumn{6}{|c|}{ Mean values over six seasons } & $0 \cdot 0482$ & & $9 \cdot 98$ & $5 \cdot 05$ \\
\hline
\end{tabular}

providing a biased sample, the mean genotypic value of which is higher than that of the remaining plants in the field. It is impossible to provide a truly average sample, but the heritability of yield based on measurements from single plants is very low-so low in fact that attempts to improve yield by single plant selection have long since been abandoned at Namulonge. Under these circumstances the chances of genetic improvement by mass selection are very slight. This suggestion does not account for the selection differential within the sample: any improvement that might have been achieved would be inherent in the whole sample. There are no grounds for thinking that such a bias is an effective force.

The second suggestion, this time applicable to the selection differential within the sample, was that selected traits and yield could be related in a non-linear manner: alternatively, one or more of the modally selected traits could be non-normally distributed. Manning himself pointed out, however, that a selection differential of 4 per cent. (the revised value is 3.4 per cent.) could only lead to a very small 
improvement because of the low heritability of yield. It will become clear that deviations from normality are consequential, and not themselves causal mechanisms.

The third possibility was attributed to Comstock, who stressed that automatic selection follows from the close relationship of lint yield (and hence seed yield) with seed number. Manning's calculations indicated that in this way an improvement of $I \cdot 7$ to 2.5 per cent. could arise, but these figures can now be revised. Table 4 shows the estimation of selection differentials with weighting for seed number differences. The agreement between actual and estimated differentials is less using data from six years than it is if only the three used by Manning are taken. Estimated differentials are twice the size of the unweighted figures and it is inadvisable to use a value of more than 7.5 per cent. As the heritability of yield does not reach a value of $0 \cdot 1$ when measured on a single plant basis the maximum expected annual improvement is 0.75 per cent. Like the first point made this idea in no way accounts for intra-sample selection, and is unlikely to be a significant cause of advance. Comstock's formulæ express the conclusion that if plants produce equal total weights of seeds of differing average individual seed weights, then, in the absence of selective forces, small seeded types will be at an advantage in the subsequent population. A slight drop in mean seed weight did occur, but was insignificant, and it is concluded that such automatic selection is of minor importance.

\section{(ii) The hypothesis of control by dominance and heterosis}

Evidence is needed to show specifically how modal selection can cause changes detectable by yield trend analysis. It is considered here that existing evidence suggests a mechanism based on the genetic control of the characters, and that the key to the problem lies in the presence of heterozygosity and dominance.

A selection cycle may be viewed in the following sequence. Lint per seed, a trait known to be inherited in $\mathrm{BP}_{52}$ largely in an additive manner, is measured on each plant in the random sample. Amounts of genotypic interaction variance found so far have been very low, as have estimates of the degree of dominance evaluated by North Carolina techniques (Walker, 1963a). Complete homozygotes will fall at the extremes of the range and be eliminated by modal selection, whilst heterozygotes generated by cross pollination will approximate more closely to the mid-parental value. Frequency distributions (fig. 2) scarcely deviate from normality.

The next stage is that of selecting on seed weight, a character positively correlated with lint per seed: in 1962-63, for example, $r=0.5^{8}$ for 198 degrees of freedom. Inter-trait correlations are to be expected as the amount of lint borne on the surface of the seed cannot be independent of the weight and surface area of the seed and of the 
weight and length of individual hairs. At this stage the population already contains a preponderance of heterozygotes compared with the original sample, and some of the genotypes giving extreme seed weight values will have been eliminated. Dominance variance is detected by analysis of seed weight, together with slight deviations from the normal distribution curve.

In stage three lint length is considered, and we have to explain the positive trend over the first six generations. There is evidence of a genetic change in $\mathrm{BP}_{52}$ with regard to lint length during the selection project, and dominance appears to have played an important part. The $\mathrm{BP}_{52}$ population which was first subjected to secondary selection in 1947 comprised a large number of selections from many different localities. These sub-populations had not undergone directional selection for lint length and we suppose that this character was determined by polygenic combinations largely of the balanced homozygote type. Additive differences were easily detectable in the early part of the project, and there was evidence that some dominance was involved. Fig. I $a$ shows an $\mathrm{F}_{1}$ diallel $W_{r} / V_{r}$ graph for lint length from a trial involving $\mathrm{BP}_{52}$ progenies selected in $195^{\circ}, 195^{2}$ and 1955 , pedigree details being given elsewhere (Walker, I963b). The graph indicates that both additive and dominance effects exist, the point of intercept of the $W_{r} / V_{r}$ regression line with the $W_{r}$ axis showing apparent overdominance. The slope of the line is such that non-allelic interactions are indicated. These interactions cannot be ascribed to any one array, but the simultaneous exclusion of $\mathrm{C}\left(5^{\circ}\right) 20$ and $\mathrm{C}(55) 47$ eliminates the interactions and alters the genetic interpretation. This procedure was devised by Jinks (1955). Fig. Iob shows the situation in the larger sub-sample. The slope of the $W_{r} / V_{r}$ regression line ( $b=\mathrm{I} \cdot 25 \pm 0 \cdot 15)$, whilst differing significantly from zero does not do so from unity, and though dominance is still found it is incomplete. The non-interacting lines had advanced since $\mathrm{C}(50) 20$ left the selection regime, and marked heterosis for yield and other characters has been found in crosses of $\mathrm{C}(50) 20$ with lines selected in 1952 and 1955 . The presence of non-allelic interactions here is not surprising. The $\mathrm{C}(55) 47$ genotype differs from those of other 1955 progenies in its crossing behaviour. High yielding hybrids are produced only occasionally in specific crosses, many $F_{1} s$ being poorer than the lower-yielding parent in the cross.

It appears that, in general, genetic differences in lint length between hybrids of inbred lines of $\mathrm{BP}_{52}$ at the same stage of development are due mainly to additive effects and partial dominance, so that such hybrids do not fall outside the parental range. The population mean will not exceed that of the longest-linted individual inbred. The occasional specific interactions are detectable by diallel analysis.

In the modal population, heterozygotes produced by natural crossing are favoured by modal selection for lint per seed and correlated characters. Positive dominance of lint length will mean that hybrids 
have lint of greater length than the mid-parental value; the population mean value will increase and eventually reach a plateau. In such circumstances linkage will delay the breakdown of balanced homozygotes with phenotypic values towards the extremities of the range and will thus accelerate their removal. Linkage will also delay the

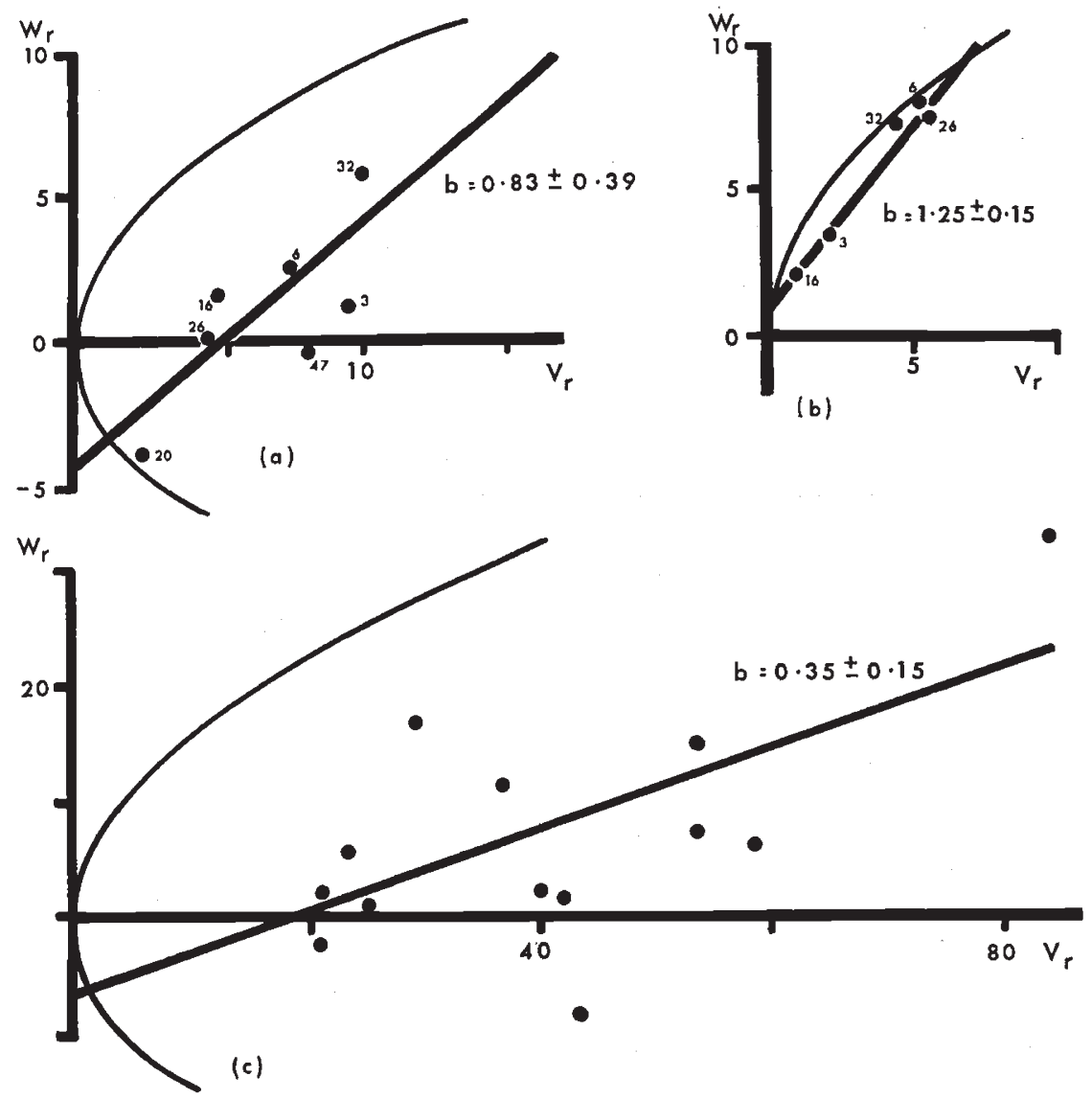

Fic. 10.- $\mathrm{F}_{1}$ diallel graphs for lint length in $\mathrm{BP}_{52}$. (a) First series trials, seven arrays, apparent overdominance indicated. (b) Two arrays excluded, dominance only partial. (c) Second series trials, thirteen arrays, showing heterozygosity and non-allelic interactions.

breakdown of heterozygotes once they are formed. It is to be expected that with this dominance control mechanism the degree of heterozygosity in the system should increase to a certain extent, and it can be shown that there is more heterozygosity in the system in the later stages of the programme than was present at the time of the diallel series from which figs. Io $a$ and $10 b$ were obtained. Fig. Io $c$ shows that non-allelic interactions are present in crosses between $12 \mathrm{MB}$ and contemporary 1959 selections, and additionally that there is considerable heterozygosity as witnessed by the dispersion of points in the vertical plane about the regression line. In complete contrast to the 
1955 series diallels the complications here cannot be removed by considering a few arrays in turn.

Just as dominance can be regarded as an effective controlling factor in the lint length advance it can also be regarded in the same way with respect to the yield increase. There is evidence from studies of crossing within $\mathrm{BP}_{52}$ that in Uganda the hybrid state is frequently associated with yield increases over the inbred lines. In the first diallel series considered above, for example, the mean yields of hybrids and inbreds when all arrays were considered were 790 and 672 units respectively, an increase of 18 per cent. The analysis of variance of yield according to the method of Hayman (1954) is given in table 5.

The significant $a$ item shows that there is genetic variation between the lines tested and the $b$ item indicates that dominance is present. The $b_{1}$ term measures the difference between inbreds and $\mathrm{F}_{1} \mathrm{~s}$, proving

TABLE 5

Analysis of variance of lint yield, $B P_{52}$ first series $F_{1}$ diallel trial

\begin{tabular}{|c|c|c|c|c|}
\hline Item & d.f. & m.s. & V.R. & $\mathbf{P}$ \\
\hline $\begin{array}{l}a \\
b \\
b_{1} \\
b_{2} \\
b_{3}\end{array}$ & $\begin{array}{r}6 \\
21 \\
1 \\
6 \\
14\end{array}$ & $\begin{array}{r}5,152 \\
2,010 \\
12,223 \\
1,783 \\
1,379\end{array}$ & $\begin{array}{r}4 \cdot 51 \\
1 \cdot 73 \\
33 \cdot 76 \\
3 \cdot 27\end{array}$ & $\begin{array}{r}<0.01 \\
<0.05 \\
<0.01 \\
<0.05 \\
\text { N/S }\end{array}$ \\
\hline
\end{tabular}

Mean squares tested against individual item $\times$ replication interactions.

strong directional dominance. $b_{2}$ measures the constancy of the dominance effect over arrays, so that in this analysis dominance is more marked in some arrays than in others. In fact the deviation here is attributable to the $\mathrm{C}(55) 47$ array, the inbred line showing poor combining ability. If this array is excluded the $b_{2}$ item is nonsignificant and the means of hybrids and inbreds become 799 and 632 units respectively, an advantage of 26 per cent. in favour of the hybrids. Specific differences between parental and $F_{1}$ means were not significant $\left(b_{3}\right.$ item).

In considering the inheritance of yield we thus not only have high dominance but apparent overdominance, and diallel analysis strongly suggests that the heterotic effect is due to non-allelic interaction. Heterosis is shown in $\mathrm{BP}_{52}$ not only in yield but in seedling and other vegetative growth characters, and the heterozygous condition has probably become advantageous under the action of natural selection. This statement is supported by the tendency for modal yield advance in $\mathrm{BP}_{52}$ to be greater at Namulonge where the selection was practised than elsewhere, implying environmental specificity in heterozygote advantage. Under modal selection an equilibrium will be attained in yield as in the case of lint length, but the increases will be protracted 
because the dominance effect is much stronger for yield. The heterosis also allows the upper limit to be higher than that of the inbred plants. The statistical detection of the equilibrium will be difficult in the case of yield because of large genotype by environment yield interactions. The analysis of variance of yield in the diallel series testing I $2 \mathrm{MB}$ and contemporary I959 selections shows significant genotype by environment interactions, while the $W_{r} / V_{r}$ graph (fig. II) shows heterozygosity, dominance and non-allelic interactions.

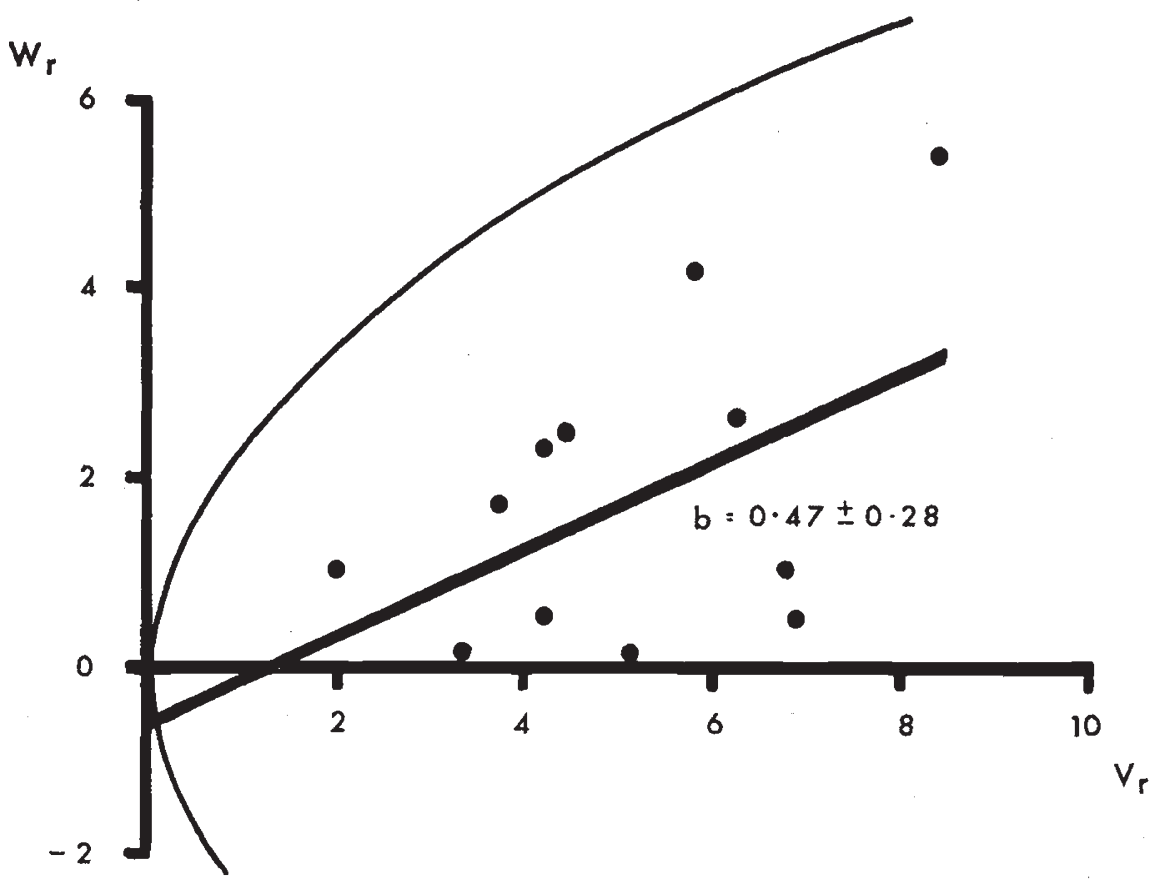

FIG. 11.- $\mathrm{F}_{1}$ diallel graph for yield in $\mathrm{BP}_{52}$ indicating heterozygosity, dominance and non-allelic interactions. Second series trial.

If the hypothesis of control by dominance and heterosis is tenable it follows that the order in which traits are subjected to modal selection should influence the size of the selection differential. To ensure maximal heterozygosity those characters most near to being determined in an entirely additive manner should be measured first, and as yield is influenced by heterozygosity the selection differential should be larger when additive traits are considered first than when they are at the end of the sequence. Evidence to support this contention is offered in the form of results based on $\mathrm{BP}_{52} 9 \mathrm{MB}$ (for which all characters were measured on all plants in the sample), and given here in table 6. Modal selection was carried out both in the standard sequence and in the reverse order, after which yield selection differentials were evaluated. Different individual plants passed through the two "sieves" and the mean yields of the two selected populations differed. In accordance with theory the greater response was obtained 
when selecting in the standard order. Increased accuracy was obtained in these calculations by taking smaller class intervals than usual in

TABLE 6

\begin{tabular}{|c|c|c|c|c|c|}
\hline Order of selection & $\begin{array}{l}\text { Sample } \\
\text { size }\end{array}$ & $\begin{array}{c}\text { Plants } \\
\text { left }\end{array}$ & $\begin{array}{l}\text { Mean } \\
\text { yield }\end{array}$ & $\begin{array}{l}\text { G.V. } \\
\text { yield }\end{array}$ & $\begin{array}{l}\text { Percentage } \\
\text { advance }\end{array}$ \\
\hline $\begin{array}{l}\text { Standard (L/S, S.W., L.L.) } \\
\text { Reverse (L.L., S.W., L/S) }\end{array}$ & $\begin{array}{l}298 \\
298\end{array}$ & $\begin{array}{l}112 \\
114\end{array}$ & $\begin{array}{l}29 \cdot 46 \\
29 \cdot 08\end{array}$ & $\begin{array}{l}32 \cdot 5 \\
32 \cdot 7\end{array}$ & $\begin{array}{l}6 \cdot 1 \\
4 \cdot 7\end{array}$ \\
\hline
\end{tabular}

routine practice, and this accounts for increased percentage advance estimates here compared with the one obtained when IOMB was actually derived.

\section{DISCUSSION}

The detection of heterosis within the $\mathrm{BP}_{52}$ variety (Walker, $1963_{3} b$ ) provides a basis for the explanation of the yield trend detected by Manning in the $\mathrm{BP}_{52}$ Modal Bulks. That Manning's yield advance estimates were inflated by genotype by environment interactions is of relatively small consequence in view of the interest that his report caused and the consequent study of the biological systems involved. It is considered that the explanation proposed above based on dominance and heterosis is the most satisfactory to date, differing as it does from mechanisms previously suggested in that it takes account of the natural cross-fertilisation found at Namulonge and ignored in other hypotheses.

Consideration of a situation in which only a few genes are operating in a Mendelian fashion shows that if dominance is the controlling factor then cross-fertilisation is obligatory for advancement. Segregation and inbreeding coupled with modal selection lead to a reduction of heterozygosity, because although extreme homozygotes are removed continuously the selection process is unable to differentiate between heterozygotes and balanced homozygotes with the same phenotypic score. Under random mating an equilibrium is attained through the production of balanced homozygotes and the regeneration of heterozygotes by outcrossing.

There are no strictly comparable results involving yield trends in crops other than cotton in which stabilising selection has been practised, but work on a bulk-hybrid population of barley reported by Jain and Allard (1960) and Jain (I961) is worthy of attention here. Their barley populations were derived from a hybrid composite, and so inevitably showed a decreased variance in the character that they studied, which was heading time. The mean decreased slightly, and we may interpret this as indicating that the trait showed slight, partial dominance for earliness. The presence of marker genes enabled the population to be analysed in terms of genotypic frequencies at the 
marker loci. Eighteen generations were grown, the mating system being predominantly (98-99 per cent.) selfing. The decay in heterozygosity at several loci was slower than expected with the low degree of outcrossing, so Jain and Allard postulated heterozygote advantage, concluding that their results conformed with the homeostasis model of Lerner (1954) for stabilising selection rather than with the theory of the intermediate optimum (Wright, I95I).

Robertson (1956) also considered the theories of Wright and Lerner in his theoretical study of stabilising selection, and concluded that selection of intermediates leads eventually to gene fixation. He decided that Lerner's model was much the more fruitful of the two, and pointed out that on the Wright hypothesis gene frequencies tend either to zero or to unity so that if it does operate in practice it cannot possibly maintain variation in a population.

Jain ( $196 \mathrm{I}$ ) plotted heading time against fitness as measured by seed number, and there was neither a significant correlation nor a parabolic distribution of points, thus providing further evidence of heterozygote advantage. We may compare this situation with modal selection for lint per seed in $\mathrm{BP}_{52}$. In fig. I 2 Jain's plotting procedure has been repeated for fitness and lint per seed, and here too there is no correlation between the traits. The pattern of points shows triangulation, with high seed numbers tending to be associated with the middle of the range of the lint per seed values (i.e. with heterozygotes, for this character shows no dominance). We expect this on both hypotheses, as well as on the basis of the intra-season selection differentials. Values of the two traits for the 200 plants of $15 \mathrm{MB}$ grown in $1962-63$ were used in fig. 12 . It can be seen that the distribution shows no convexity, plenty of plants in the middle of the range of lint per seed showing low seed production, and we may suppose that these are balanced homozygotes. The fact that the variance of lint per seed did not decrease under modal selection is itself strong evidence that heterozygosity was maintained because it was at a selective advantage, and deductions from fig. I 2 reinforce this viewpoint. Plants intermediate in value for some traits tend to be the most fit in $\mathrm{BP}_{52}$, but only when the measured character shows little dominance and because fitness shows a high degree of dominance or even apparent overdominance. We must conclude that those plants from the middle of the range that produce more seed do so because they are heterozygous and not because they show an intermediate value for lint per seed. It seems reasonable to suppose that dominance for fitness has evolved under natural selection; it is difficult to see why plants should be more productive because they show modal values of a trait that can have been subject to relatively little selection pressure in nature. The results from the $\mathrm{BP}_{52}$ study, where they show stabilisation of trait means, lend strong support to Lerner's theory.

Other cotton workers who have tried modal selection as a technique for yield improvement probably expected too much too quickly, 
because Manning somewhat overestimated the size of the yield advance in $\mathrm{BP}_{52}$. Extensive experimentation involving adequate replication is necessary to detect small changes. Lee (I962) described three generations of modal selection in Nigerian Upland cotton, and

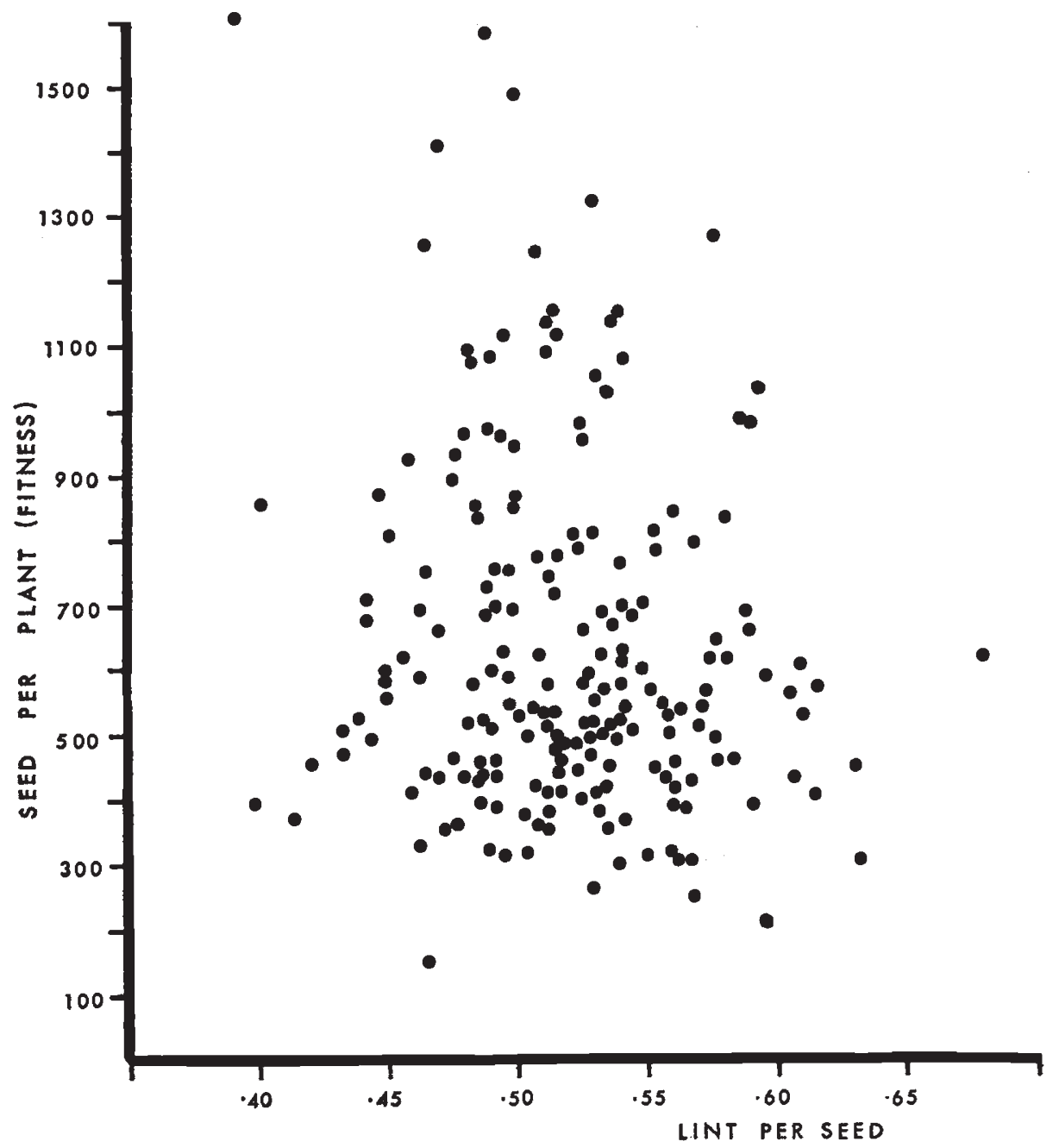

Fic. 12.-Fitness, as measured by seed number, plotted against lint per seed for $15 \mathrm{MB}$. Two hundred plants.

concluded that the genotypic variance in the strain that he used was inadequate to respond to modal selection. The degree of outcrossing may be lower in Northern Nigeria than the 20-30 per cent. usual at Namulonge, and this might have affected the issue, but only six field trials involving a total of 34 replications were grown. Two trials compared IMB with the original bulk, and four compared $2 \mathrm{MB}$ with IMB. Testing on such a small scale is inadequate. The selection method has been used with other stocks of Upland cotton in various 
African countries, but insufficient data have been accumulated to allow adequate tests for yield advances to be made.

It would appear that for the modal selection system to effect significant change in the ultimate character considered the following circumstances are necessary:-

I. At least one of the traits used, preferably the first, must show mainly additive genetic variation.

2. Other preliminary traits should be correlated with the first character selected.

3. The final trait should show high dominance.

4. A certain amount of natural or artificial self-pollination should occur, but the mating system should not ensure complete outcrossing.

The technique is useful only in crops in which there is no selfincompatibility system or other such method more efficient than this modal one for ensuring heterozygosity. Some outcrossing is necessary, but quite modest values of this and of the degree of dominance of yield will probably suffice to counteract inbreeding depression in cotton. The constitution of modal bulks of selected lines may ensure them against the "running down" usually attributed to mutation, crossing with poor types and relaxation of selection.

As a cotton breeding method modal bulking cannot be expected to produce yield increases of more than I or 2 per cent. per annum, especially as there are other factors present under Uganda cotton growing conditions that may have affected the results of the $\mathrm{BP}_{52}$ selection experiments. Seedling competition is strong because at least five seeds are sown by hand in each planting hole, and selection bias acting in favour of heterozygotes showing vegetative heterosis is superimposed by agricultural workers during the singling operation (Walker, $1963 b$ ). This competition is removed if both sowing and thinning are mechanical. Perhaps the modal bulk technique has its highest potential in maintaining lines or varieties with possible future commercial prospects. The practice should conserve genetic variation and insure against deterioration, provided the conditions laid down above are fulfilled. The principle is contrary to orthodox schemes for the maintenance of seed stocks, in which precautions are usually taken to prevent cross-fertilisation.

\section{SUMMARY}

I. A description is given of an open-pollinated modal selection system designed by $\mathrm{H}$. L. Manning to stabilise cotton lint yield and reduce its variance.

2. Results from sample populations show that both the mean and variance of lint per seed and seed weight remained constant over is. generations. Lint length increased rapidly over 5 generations whilst 
its variance decreased, but not significantly; thereafter the mean was stable but the variance increased.

3. Where stabilisation occurred the results conform with the homeostasis model of Lerner involving heterozygote advantage rather than with Wright's theory of the intermediate optimum.

4. The most reliable analysis of the lint yield trend uses results from trials from a large area of Uganda and shows an increase of I per cent. per generation over Io years. Interactions of genotype with environment are involved in the expression of yield.

5. Mechanisms previously suggested as causes of the yield trend are discussed and rejected. Inheritance of the selected traits is such that selection favours heterozygotes. The increase in lint length is attributable to partial dominance; that in yield to heterosis involving non-allelic interaction.

6. Equilibria are attained with modal selection in cotton because of the concurrent production of heterozygotes by outcrossing and of balanced homozygotes by inbreeding.

7. Reversal of the order in which characters are selected influences the resultant changes.

8. Conditions are given under which modal selection may lead to useful genetic gain. If used as a breeding system it may conserve genetic variability.

Acknowledgments.-The writer is greatly indebted to Mr H. L. Manning for providing the experimental populations and data from the early years of this study. Acknowledgment is also made of helpful discussion with $\mathrm{Mr}$ Manning, with Professor Sir Joseph Hutchinson, F.R.S., and with Professor K. Mather, F.R.S., as well as with colleagues at Birmingham and Namulonge. This account was written whilst on study leave generously given by the Empire Cotton Growing Corporation, and is part of a study approved by the University of London for the Ph.D. degree.

\section{REFERENCES}

HAYMAN, B. I. I954. The analysis of variance of diallel tables. Biometrics, ro, 235-244.

JAIN, s. K., AND ALlaRD, R. w. r96o. Population studies in predominantly selfpollinated species. I. Evidence for heterozygote advantage in a closed population of barley. Proc. nat. Acad. Sci., Wash., 46, 1371-1377.

JAIN, s. K. r96r. Stabilizing selection for heading time in a bulk-hybrid population of barley. Nature, Lond., r 91 , I I 23-I 124.

JINKs, J. L. I955. A survey of the genetical basis of heterosis in a variety of diallel crosses. Heredity, 9, 223-238.

LEE, B. J. S. I962. Modal and positive bulks in plant breeding. Emp. Cott. Gr. Rev., $39, \mathrm{I} 8 \mathrm{I}-\mathrm{I} 87$.

LERNER, I. M. I954. Genetic Homeostasis. Oliver and Boyd, Edinburgh and London. Pp. 99-107.

MANNing, H. L. I955. Response to selection for yield in cotton. Cold Spr. Harb. Symp. quant. Biol., 20, 103-I 10.

MANNING, H. L. I956. Yield improvement from a selection index technique with cotton. Heredity, ro, 303-322. 
MANNING, н. L. 1963. Realized yield improvement from twelve generations of progeny selection in a variety of Upland cotton. Stat. Genet. $\&$ Pl. Br., NAS-NRG 982, 329-349.

MATHER, K. 1953. The genetical structure of populations. Symp. Soc. exp. Biol. VII. Evolution, 66-95.

ROBERTSON, A. 1956. The effect of selection against extreme deviants based on deviation or on homozygosis. 7. Genet., 54, 236-248.

WALKER, J. T. 1960. The use of a selection index technique in the analysis of progeny row data. Emp. Cott. Gr. Rev., 37, 81-107.

WALKER, J. T. I963a. The average degree of dominance of genes determining components of lint yield in the $\mathrm{BP}_{52}$ Upland cotton variety. Proc. XI Intern. Congr. Genet., 223.

WALKer, J. T. 1963b. Multiline concept and intra-varietal heterosis. Emp. Cott. Gr. Rev., $40,190-215$.

WRIGHT, s. 1956. Modes of selection. Amer. Nat., 9o, 5-24. 